\title{
From Traditional Culture Education, the Application of Peking Opera Facial Elements in Poster Design Teaching
}

\author{
Dan $\mathrm{Xu}{ }^{1}$, Zexian $\mathrm{Nie}^{2}$ and Wenquan Zhou ${ }^{3}$ \\ ${ }^{1}$ City College of Wuhan University of Science and Technology, Wuhan 430083, China \\ ${ }^{2}$ City College of Wuhan University of Science and Technology, Wuhan 430083, China \\ ${ }^{3}$ City College of Wuhan University of Science and Technology, Wuhan 430083, China \\ * Corresponding author Ying Yu
}

\begin{abstract}
Keywords: Traditional culture education; Peking Opera elements; Poster design
\end{abstract}
\begin{abstract}
Chinese art of Peking opera mask keep up Chinese traditional cultural elements, which are not only reflected in colorful mental aspects, but also appear modern graphics with traditional cultural elements. Although the Peking Opera Mask originated from stage, different styles of mask images can be found in some grand buildings, goods packages, all sorts of china and also clothes. The essay studies the integration of mask elements into poster design. It focuses on the relationship between mask and poster design in terms of inner spirit and design effects of poster design and traditional element in order to make it used in poster more widely and deeply, which set a new fashion of integrating cultural elements into poster design and its influence on the use of image in poster design.
\end{abstract}

\section{Introduction}

The essay analyses the integration of Chinese traditional culture, Peking opera, into modern poster design and to be specific, mask elements adoption in poster design. The essay reveals the inner truth of facial mask and the regular form, beauty feature and representation in visual design to study the relationship of mask and poster design in terms of inner spirit and creating effect. The color effect of red color is widely spread through Peking Opera mask. The introduction and guidance of color can arouse people's interest in products. Surrounded by the ocean of colorful multimedia where color trend varied day by day, people are numb with all appearance of color.

How to combine the facial mask and poster design? Firstly, to understand the inner truth of Peking opera. Secondly, investigate the development of mask appliance in poster design and also the regular form, beauty feature and representation of mask in visual design. Thirdly, the interrelationship of modern and traditional culture. Unavoidably, there is violent crash between modern and traditional culture, which, however, brings strong life to the traditional pattern, and lay deepened culture basis and promote broader development for modern graphic design.

\section{Design Conception}

Design Theory

Universally acknowledged as quintessence by the majority of Chinese including overseas Chinese, Peking Opera is the crystallization of Chinese traditional culture, and is the symbol reflecting nation dignity and national spirit and also our custom. and is also regarded as the most typical representative. The redesign of Chinese elements in graphic design makes people apparently feel the Chinese origin of the design. It is the soul and structure rather than the content that matter; it is the inner spirit, not just simple shapes joined or cut that counts.

Chinese traditional element is an unique spectacular and precious wealth. With its long history and rich inner meaning, Chinese Opera can never be replaced by other art forms. Compared with other elements such as calligraphy, seal cutting, opera culture is extraordinarily outstanding with its unique oriental culture, and are always more likely to resonate with consumers as emotional bond between chinese and culture. I adopted four famous opera characters in this series of poster design 
and try to represent their individual characteristics with various abstract shapes and different colors.

Design style

In the poster design series, every image features elegance, chic, primitive simplicity and solemnity like opera, and also follows the popular trend of modern society. Corresponding to its theme Coming From Traditional Culture, the series take advantage of the unique art features to represent unconventional characteristics in the traditional culture. Supported by seal cutting and calligraphy, facial mask is integrated into Chinese ancient characters, which attracted spectators deeply by this kind of art language. The mixture of all kinds of irregular geometry impresses people with profound national tradition and modern fashion. Chinese opera mask is integrated with irregular geometry, which impress people with the combination of tradition and modern. As far as I am concerned, only if we integrate the popular and fashionable concept into traditional and national elements of poster design, can we meet the requirements of contemporary society, can the sustainability of traditional elements be developed in the changing times. Of course, modernity does not necessarily means popularity, but it is for sure that pop factors must be contained in modern concept.

Innovation of the design

Chinese traditional element is an unique spectacular and precious wealth. With its long history and rich inner meaning, it can never be replaced by other art forms. In the world stage of art, opera culture is extraordinarily outstanding with its unique oriental culture. However, inheritance doesn't mean copying completely. It never makes it without innovation. Art needs innovation. The sustainability of art requires that we should not completely deny previous culture. So, it should be positively negative, to be specific, artists should absorb the essence while discard the dross, as ancient people said. The innovation should be based on deep understanding of the representation of traditional art and it should be refined and practiced to be equipped with more modern features.

This series of poster design themed Coming From Traditional Culture mainly reflects the representation and integration of traditional elements in modern graphic design. With its long history and rich inner meaning, opera can never be replaced by other art forms. With its long history and rich inner meaning, it can never be replaced by other art forms. Compared with other art forms, opera culture is extraordinarily outstanding with its unique oriental culture, and are always more likely to resonate with consumers as emotional bond between Chinese and culture. I adopted four famous opera characters in this series of poster design and try to represent their individual characteristics with various abstract shapes and different colors. As a traditional color, red is widely used in facial mask. There are a great number of red roles in Peking Opera, most of whom are main characters, playing decisive roles and representing the country dignity and national spirit indirectly. All these make people feel the Chinese origin of my design for its own soul and structures.

The series of poster design themed Coming From Traditional Culture is intended for Chinese quintessence exhibition, the aim of which it to have people understand the development of opera from ancient times until today. Chinese opera make its uniqueness in a conventional way. But now, the uniqueness is maintained by the combination of eastern and western designs despite the crashing of the design theories from two parts. Corresponding to its theme Coming From Traditional Culture, the series take advantage of the unique art features to represent unconventional characteristics in the traditional culture. Shaped like an ancient girl's face half-covered, the facial mask integrated into Chinese ancient characters, which attracted spectators deeply by this kind of language. These different mask are elegant, chic, traditional or serious, which remind audience of their old times.Chinese opera mask is integrated with irregular geometry, which impress people with the combination of tradition and modern. The different colors of facial masks contribute a lot to convey the different characteristics of characters. I mainly use red, black, white, yellow and so on, which are common in Peking Opera. Red symbolize royalty, which features the courageous characters. Black represents characters with integrity, selflessness, while white represents characters with cunning, arrogance. I always use black color in some brave and battle-wise figure. The exaggeration of skin color reflects the character description. 


\section{Series design}

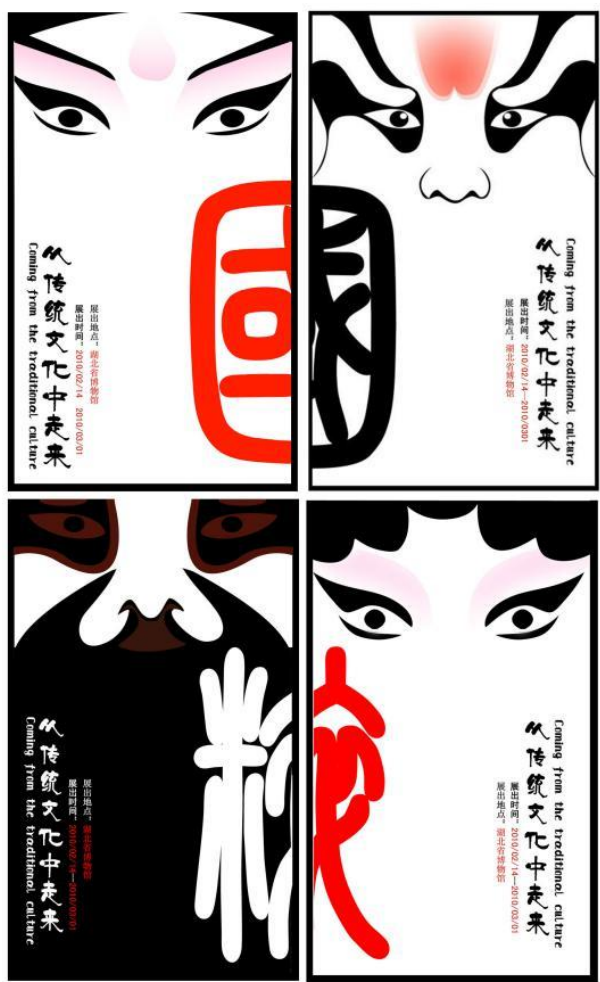

figure 1
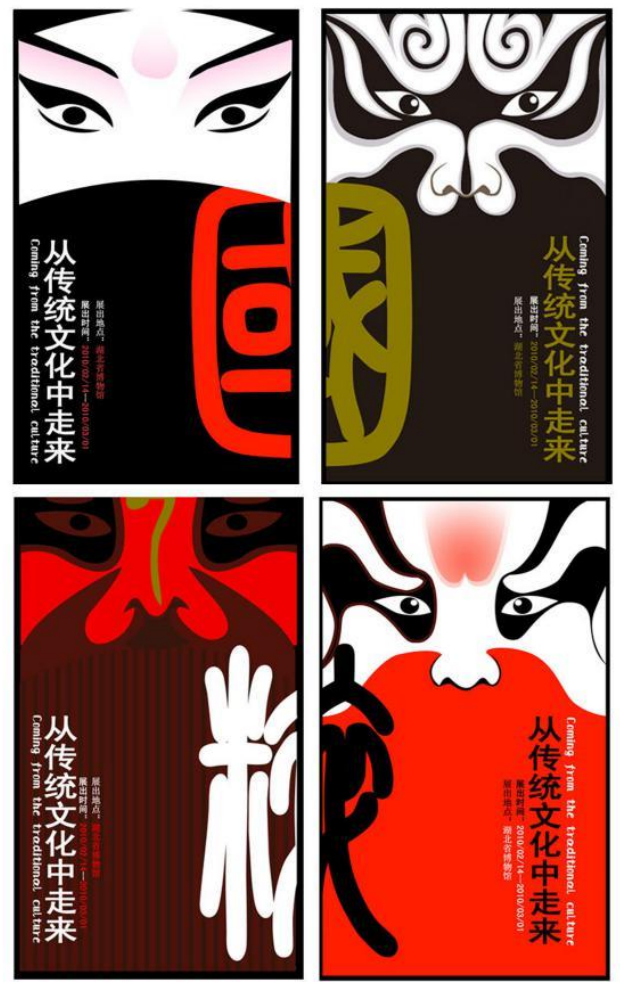

figure 2

figure 1:The above are the sketches with facial masks as main design elements. Different images are emphasized by irregular shapes. The colors and patterns from facial masks changes according to difference of masks.

figure 2: The above are the improved designs whose basic shape and main colored are fixed. This series of poster design's prototype comes from traditional Peking opera and adjusted with different mask shape. It main colors are black and red.

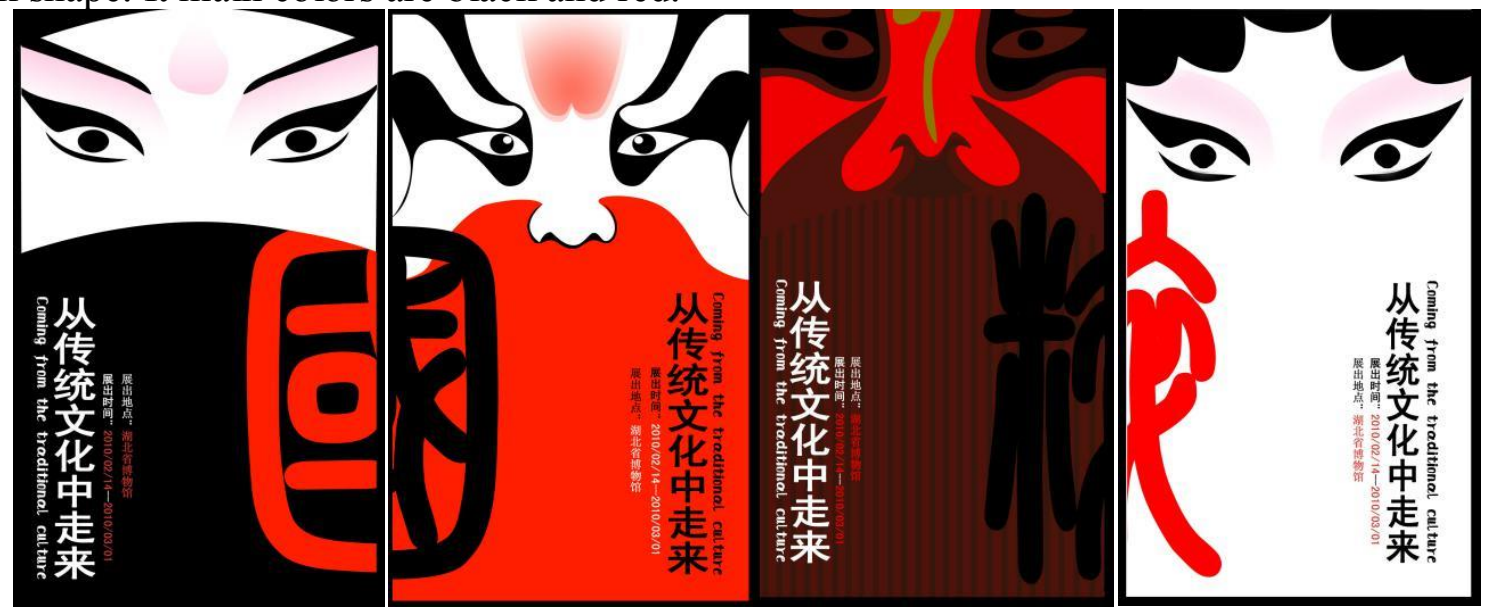

figure 3 Final effect diagram

\section{Summary}

The four poster designs themed Coming From Traditional Culture is intended for the great Chinese Peking Opera Mask Exhibition and represents the combination of traditional elements and modern design. Talking about traditional culture, i firstly think of Peking Opera Mask whose art model and color usage fully represent Chinese tradition. With red as its main color, opera combine the Chinese traditional graphic design and foreign design, which is not only the inherit of Chinese art spirit but also make it widely known to the whole world. Deepened thoughts of Chinese traditional graphic design are required in our time. Only when we have figured out the common symbol of all cultures 
can we build an international band. Chinese traditional cultural elements are integrated into poster design, which not only thoroughly represent our oriental mystery but also function as international broadcast and communication. It has been a tendency to adopt traditional elements in modern poster design. Tradition featured design has been the main trend in the future. Therefore, we artists should be based on Chinese culture while accepting other designs, which means we need to respect uniqueness of Chinese art and aesthetics of Chinese people, but also reflect the inner soul pursuit of modern people.

\section{Acknowledgements}

Humanity and Society Science Project by Ministry of Education of Hubei Province

Project Theme: research on the practicality of Chinese traditional graphs language integrated into modern graphs design

Project Code: 16G249

\section{References}

[1] Tang Yiyong: poster design (Shanghai people's fine arts publishing house, China 2015), p. 10-32

[2] Wei Jie: Graphically creative (China building industry press, 2013), p. 32-50

[3] WuBin , Cao Li: Design thinking and creative (Beijing university press, 2016), p. 22-53

[4] HongQiong: Traditional Chinese folk art (huazhong university of science and technology publishing house, China's 2016), p. 12- 45

[5] [Japan] hengshan shot: The design thinking (people's posts and telecommunications publishing house, China, 2017), p. 28-46

[6] Donald a. Norman : design psychology (China citic publishing house, 2016), p. 56-70

[7] HangHai,Lin Cunzhen: The application of the nationality traditional culture element in modern art design research (China building industry press, 2017), p. 38-66

[8] Yan-qing Chen: Multiple forms and inheritance (China textile press, 2018), p. 15-49

[9] Zhang Jianchun: Photoshop masters (China electric power press, 2014), p. 27-54

[10] MeiReHeng: Beijing Opera so beautiful (citic publishing house, 2017) of China, citic publishing house, 2017 